PLENÁRIAS EIXO 2:

"PSICANÁLISE: DIÁLOGO NAS FRONTEIRAS" 


\section{Psicanálise no umbral ${ }^{86}$}

\section{Elizabeth Chapuy ${ }^{87}$}

Em 1936, na casa da rua Berggasse, um grupo de achegados e notáveis participantes se reuniram para comemorar o octagésimo aniversário de Freud, ocasião na qual Thomas Mann leu um requintado texto em honra ao homenageado, destacando:

A importante obra de Freud, em cada esfera de seu trabalho, como médico e psicólogo, como filósofo e artista, este intrépido descobridor foi, durante duas gerações, um guia através das regiões da mente humana até então inexploradas. Espírito completamente independente, um 'homem e cavalheiro de olhar ousado', como Nietzche disse de Schopenhauer, um pensador e investigador que pode resistir sozinho e, além disso, atrair a si muitos.

Os conceitos que ele encontra, as palavras que escolhe para eles, se tornaram já integrantes evidentes, de todo o idioma vivo; em todos os campos das ciências do homem, no estudo da literatura e na arte, a história das religiões e a pré-história, a mitologia, o folclore e a pedagogia e, por certo que na poesia mesma, podemos discernir a marca profunda da sua influência, e, se alguma vez a raça humana alcançou uma conquista inesquecível esta é, com certeza, seu descobrimento da ciência da mente.

Início minha conversa com vocês com este belo relato para dizer que o berço no qual nasce a psicanálise se localiza na fronteira, foi o próprio Freud quem, com passo intrépido e ousado, sem ser artista, nem filósofo, nem físico, nem historiador, nem antropólogo, nem literato, transitou por todas essas disciplinas com a liberdade de quem as concebe como o lugar onde sucedem os acontecimentos, não acatando o limite demarcatório, mas tomando as complexidades dos entrecruzamentos e interfaces que subvertem a existência do prévio e dão origem ao novo.

Freud havia dito de seu Moisés: sei que estou me intrometendo em um terreno que não é o meu, não sou historiador, não tenho fundamento. No entanto,

\footnotetext{
86 Trabalho apresentado na plenária ““Psicanálise: diálogo nas fronteiras” no II Simpósio Bienal SBPSP "Fronteiras da Psicanálise: a clínica em movimento", no dia 28 de agosto de 2020.

87 Diretora Científica de Fepal, Membro efetivo da Associação Psicanalítica de Cordoba.
} 
se atreveu a transitar um caminho sobre um "fundamento desfundado", porque só assim, interpelando os saberes consagrados, se pode fundar.

Nós, analistas, nos habilitamos a trabalhar desta maneira, nas margens dos saberes consabidos? Talvez a herança de Freud não seja outra coisa que isso.

\section{Psicanálise e estrangeiridade}

Como ponto de partida e para pensarmos juntos sobre o tema que nos convoca dizemos que a psicanálise é estrangeira e apátrida.

Por isso é que nossa conversa se dará em um território de fronteira, ou, como eu gosto de pensar, como um umbral, isto é, um ponto de contato com um espaço externo, que deve permanecer vazio e, por sua vez, ser a porta de entrada de uma casa, o lugar por onde se ingressa ao encontro com o outro.

Vivemos em uma sociedade que tende à desaparição do outro, na qual se imprime, a partir de uma política neoliberal, a uniformidade e o império do mesmo.

Falar e escutar, em uma escuta ativa, na qual possamos dar as boas vindas no umbral ao outro e reafirmar a alteridade e a diversidade, é a opção, ao meu modo de ver, de alcançar um conjunto de vozes que nascem das e nas fronteiras.

Sustentando a heterogeneidade e a diversidade com o estrangeiro, que nos remete, por sua vez, a nossa própria estrangeiridade, é o território de encontro necessário e ineludível para uma psicanálise que mantenha a sua voz com vida.

\section{Todo sujeito é sujeito de fronteira}

Aspiro a pensar, como muitos também o fazem, que a psicanálise e os psicanalistas estão em uma construção-desconstrução, na qual nunca transitamos em nosso trabalho por uma superfície homogênea, mas, ao contrário, por uma superfície rugosa, imperfeita e sempre inacabada.

Longe ficaram os dogmas do modernismo que nos falavam de segmentação e da acumulação de conhecimento na busca de um determinismo coagulado e sólido, no qual a ideia de sujeito se equiparou sempre à de indivíduo, ao indivisível, ao um, ao sujeito platônico de pura substância, assentado no fixo e incomovível. 
Registramos como se produziu uma quebra, um estalo na ideia de sujeito como um ser que se reconhece em suas origens como igual a si mesmo, com a aparição dos chamados pensadores da suspeita, quem nos noticiaram sobre a ruptura.

Foi Marx quem disse: o sujeito da história não é um indivíduo, mas uma classe social, assim como Nietzsche declarava que o sujeito é uma invenção artificial que serve para certas coisas, mas que não procuremos nele substancialidade, da mesma forma como na irrupção de Freud e seu radical enunciado, quem se encarregou de anunciar à humanidade de que o sujeito é sujeito do inconsciente; aquele que não sabe de si.

Com Freud inicia-se um trânsito que vem do sujeito da razão, nascido no Iluminismo, ao sujeito do inconsciente, que, por sua vez, é reformulado por Lacan, quem introduz uma outra genealogia na gênese do sujeito, com a prioridade do outro como fonte de significantes e sujeição às leis da linguagem e da cultura.

Hoje tampouco podemos desconhecer o sujeito da fragmentação do pós modernismo, ou ao virtual da cultura cibernética, assim como também ao sujeito da exclusão, que longe está da ideia de um mundo transparente que colapsa ante a incerteza e o desconcertante das políticas que tornam precária a vida do cidadão latino-americano.

Nesta cartografia imprecisa e móvel se localiza, ao meu modo de pensar, o sujeito humano nas margens de uma sociedade estremecida.

Daí que nos habilitamos a afirmar que a psicanálise é uma psicanálise de fronteira, o que podemos assegurar na medida em que nos animemos a abandonar categorias absolutas e incursionar nos interstícios, deixando ao lado do caminho a ideia da história como um processo evolutivo e compreendendo como os genealogistas, sua complexidade, seu movimento e seu caráter paradoxal.

Como maravilhosamente diz Gilles Deleuze em 1995:

O E não é nem um nem outro, está sempre entre os dois, é a fronteira, porque sempre há uma fronteira, uma linha de fuga ou de fluência, ainda que não se veja, ainda que seja, como é, o menos perceptível. Não obstante isso, as coisas acontecem sempre nesta linha de fuga, nela têm lugar o devir e surgem as 
revoluções. Os fortes não são aqueles que ocupam um ou outro campo, a potência está na fronteira.

No $\mathbf{E}$ que aponta Deleuze se deixa entrever a ruptura do binarismo, abre à multiplicidade atuando em simultaneidade, que requer de outros modelos de pensamento e é por aqui que aparece a lógica paradoxal, entendendo que o mais interessante deste conceito é que resulta dessa alusão ao impossível, denunciando a incompletude dos sistemas lógicos.

É uma aposta a desmontar, problematizar, tornar complexa a relação imediata e visualizar a convivência de termos aparentemente opostos, em lógicas que alberguem incertezas. Portanto, aberto ao complexo, ao mestiço que tensiona e interroga nossas teorias e nossa clínica.

Dessa forma, o desafio implica conceber uma Psicanálise que não está detida no tempo, que não permite repousar na tranquila segurança de saberes conhecidos e sacralizados, isto é, pensá-la em termo de desafios.

Este é um convite, uma convocatória a assomar-se ao abismo do desconhecido, do não pensado, em suma, a retomar o mais forte do legado freudiano.

Esta proposta tenta evitar o abrigo prodigioso de verdades provadas e aprovadas, arriscando-nos a caminhar como Moisés num exílio inquietante que empurra à intempérie do inédito.

\section{$O$ inquietante}

Se partimos por uma estrada que desejamos transitar, necessitamos de uma visão cartográfica, na qual iremos traçando, todo o tempo, mapas sempre em movimento: "mapas que se sobrepõem de tal modo que cada um encontra um retoque no seguinte, em vez de uma origem nos anteriores: de um mapa a outro, não se trata da busca de uma origem, mas de uma avaliação dos deslocamentos” (Deleuze).

Percorrendo estradas em permanente movimento, num desenho que se desdesenha, que ao ir tomando outras grafias, nos encontramos com marcos de heterogeneidade e complexidade que estabelecem os fios do tear sobre o qual vai se tecendo um diálogo de fronteira. 
Estamos dispostos a rever paradigmas e paradoxos que desafiam saberes estabelecidos e instituídos na busca de resolver a forte e tentadora inclinação a unificar contornando o diverso e paradoxal, como uma tentativa de aplacar e calar a INQUIETUDE que nos abisma ante o inexplorado.

Como fantasticamente nos diz Goethe em Fausto:

Ato quinto Cena quinta

Range a porta e ninguém a atravessa.

Assustando-se, Fausto diz: quem está aí? Inquietude responde com uma pergunta: Uma pergunta?

Fausto: Mas quem és tu?

Inquietude: Aqui estou e suficiente.

Fausto: Afaste-se daqui?

Inquietude: Estou em meu verdadeiro lugar.

Fausto: Anda com cuidado e não profiras nenhum conjuro.

Inquietude: Mesmo que o ouvido não me sinta, o peito me leva dentro; sempre em mutante figura, colérica violência exerço. No caminho, no umbral, angustiosa companheira, sempre, mesmo que não me busquem, seguramente me encontram, algumas vezes malditas, outras, cheia de lisonjas. Nunca conheceste a Inquietude?

Fausto: Cala! Então não vens trazer-me a salvação! Não posso suportar tais loucuras! Fora daqui com essa odiosa ladainha que até mesmo ao homem mais são o deixa louco.

O Fausto de Goethe mostra extraordinariamente a rejeição ao novo que submerge no sub reptício do trânsito pelo umbral, pois manda INQUIETUDE calar.

Convidar o outro a nossa casa, ser visita na casa alheia, afastar-nos de nosso povo e chegar a um povoado alheio, sustentar a diversidade, sair dos binarismos aprisionantes, permitir o estouro dos mesmos, tudo isso e muito mais que neste momento não consigo dizer, vêm pela mão de INQUIETUDE, angustiosa companheira de andanças "que mesmo que não a busques, seguramente a encontras". 
Este trânsito pressupõe uma pergunta que se apoia em uma decisão teórica: substituir o paradigma clássico da disjunção por um paradigma que tem por efeito "apresentar as interrogações em chave "E em lugar de "OU". (Morin, 1992).

\section{A psicanálise habitante de fronteiras}

Corre perigo a psicanálise neste século XXI, pelo risco de precipitar-se em uma teoria cada vez mais abstrata, que fascina por sua relação com as matemáticas, a topologia e outras disciplinas formais?

Não podemos fazer ouvidos moucos ao dito por Derrida em "Estados de ânimo da Psicanálise":

O risco da psicanálise é o de ser deportada, transbordada, deixada ao lado do caminho, exposta a todas as derivas, a todas as apropriações, a todos os raptos; ou mesmo à inversa, permanecer arraigada nas condições de uma época que foi a de seu nascimento, ainda afásico, em seu berço de nascimento centro europeu.

Há um oferecimento iniludível ao qual não podemos renunciar, tanto os psicanalistas como os artistas, como os filósofos, que é o de abrir brechas no saber consagrado, assim como nas verdades universais e aventurar-se a novas/outras perguntas, refutações e provocações.

No entanto, a experiência resiste ao conceito, e é esta resistência a que muitos chamam clínica.

Nosso ofício clínico como psicanalistas começa onde se revela o fracasso do esperado, do predizível, justamente nesse ponto em que o outro não fica subsumido em uma estrutura, aí onde a forma cede sua bravura ante $\mathrm{o}$ ato.

"Que teoria é tão autônoma que não tenha exterior, que não seja perturbada por esse exterior?" se perguntava Luis Horstein, lá pelo ano 2000. A clínica, a literatura, os pensadores pós freudianos e o panorama epistemológico em geral desvelam a psicanálise e os psicanalistas comprometidos com nosso tempo.

Os desafios não estão cindidos das marcas de cada época, muito pelo contrário, as marcas do trabalho clínico que insistem em aparecer nos interrogam e comovem, como nas velhas brincadeiras de roda infantil, que dão contorno a 
um vazio que seria ilusório/iatrogênico preencher com o já construído-sabido no século passado.

Nossa clínica é inseparável do laço social, laço social que sempre traz consigo disparidade e diferença ontológica.

A segregação, a intolerância ao estrangeiro, a crueldade e a violência deterioram e banalizam os laços sociais.

Tomando Kristeva, ela diz que os ritmos convulsivos dos acontecimentos da vida cotidiana fazem ponte com os sintomas e patologias que chegam a nosso consultório, é inevitável pensar que sempre há nexos entre a cultura e a dor humana.

Tanto Zizek em seu livro Vivendo no final dos tempos, como Dufour em $A$ arte de reduzir cabeças fazem referência a Lacan quando, em vários momentos de sua obra,

adverte que um dos problemas das gerações vindouras será a segregação como efeito da degradação do laço social, que vem fraturado desde o século XX, com a SHOA que foi a mais sinistra marca do extermínio da diferença.

A segregação e a intolerância ao diferente sempre vão de mãos dadas com a violência.

Neste sentido, Nietzsche disse: "somos herdeiros da humanidade, porém também de suas aberrações, debilidades e baixezas."

\section{Para concluir}

Não podemos ficar à margem ao falar do diálogo nas fronteiras, dos acontecimentos de grande escala social e política na atualidade, como são a crise sanitária, as migrações, o abuso do poder político, a deterioração socioeconômica e os efeitos de tudo isso na vida cotidiana.

A violência desatada pelo capitalismo avançado e seu imperativo econômico que atravessa grande parte de nossa convulsionada América Latina nos fazem colocar o foco nas fortes manifestações de descontentamento social nos países nos quais vivemos e nos de nossos irmãos, que submersos em uma potestade política cujo afã brutal por aceder a altas concentrações de poder econômico não mede/não importa as consequências na vida humana e na de outras espécies. Isso nos envolve e nos compromete a perguntar-nos sobre: 
Qual é o impacto de tudo isso na construção de subjetividades e qual é a tarefa sem desculpa e pendente dos psicanalistas ainda por realizar?

Pode nosso trabalho conjunto contribuir a ampliar nossas referências e tecer nossos saberes com outras disciplinas para dar conta das problemáticas atuais, tanto em nossos consultórios, como no mal estar da cultura contemporânea?

Estão de acordo os psicanalistas em considerar-se habitantes de fronteira?

\section{O mais além}

$\mathrm{Na}$ despedida desejo recordar junto com vocês aquilo com que nos interpelava Jacques Derrida em sua conferência ante os Estados Gerais da Psicanálise, em junho de 2000, em Paris.

Há para o pensamento psicanalítico futuro um mais além, se se pode dizer, um mais além que se sustente mais além desses possíveis que seguem sendo, tanto os princípios do prazer e de realidade, como as pulsões de morte ou de domínio (poder) soberano que parecem exercer-se onde se manifesta a crueldade?

Agradeço sinceramente este precioso convite à comissão organizadora do simpósio e às autoridades da SBPSP.

Revisão técnica: Abigail Betbedé. 